\title{
Factors Affecting Employees’ Responses to Change in Nablus Industrial Factories
}

\author{
Shuqqo $\mathbf{H}^{1 *}$ and Ghanayem $\mathbf{F}^{2}$ \\ ${ }^{1}$ Department of Industrial Engineering, An-Najah National University, Nablus, Palestine, Israel \\ ${ }^{2}$ Department of Communication Engineering, An-Najah National University, Nablus, Palestine, Israel
}

\begin{abstract}
Recently, the pressure on organizations and companies to keep up with globalization and technology leads to pay much concern on employee's engagement and responses according to development and change plans. This research aims to assess and examine factors that may lead employees to resist organizational change, a conceptual model were developed to benefit the companies who are willing to apply development processes. The research model included awareness, employee satisfaction and incentives as factors thought to be affecting company's efforts, and its analysis is established on a sample of 132 employees working in Nablus industrial factories, partial least squares structural equations modeling (PLS-SEM) was used to analyze the conceptual model. The results of the research indicate that awareness and incentives can influent the employee's responses to change, while employee's satisfaction has no significant effect. The research contributes in conducting the study in new geographical region considering different culture, religion and environmental situation. Considering that all respondents are controlled for the same working sector; small to medium size industrial companies and similar hierarchical level. It also has a potential practical contribution to the industrial factories where they can apply the results of the research according to their request while conducting the survey.
\end{abstract}

Keywords: Change resistance; Human behavior; Organizational change; Awareness; Incentives; Employee's satisfaction; PLS-SEM

\section{Introduction}

Companies new trends in human resource management focuses on the behavior and practices of their employees. Markos and Sridevi [1] conclude that employee's performance and engagement have a substantial effect on organization's vision and development. Research model claimed that many factors affecting employee's responses to change in factories.

The tendency of employees to resist change refers to the human behavior in general. It is easier to set new plans and detailed procedures rather than changing people's minds and what they used to do, as Pandit and Jain [2] emphasizes in their study, also they conclude that most people in organizations tends to resist any change because they feel comfortable with current situation and supposing that it is anyway better than anything new and unknown.

The importance of the study arises due to understanding that resistance to change can significantly influence the performance of the companies, consequently researchers and managers believe in considering the factors that negatively and positively affects the quality of applying change or development in the organizations as the most important factor [2].

Factors either negative or positive can totally affect the employees' ability to change, as Thao and Hwang [3] and Saeed et al. [4] found in their researches. The independent variables to be analyzed in this study are awareness, employee's satisfaction and incentives, and the dependent variable employee's responses to change.

Employees are highly motivated by various managerial practices such as incentives and promotions that evaluate their efforts; accordingly their performance is positively affected regardless of other factors [5]. They are also affected by awareness provided about any organizational changes and developed strategies, thus they are merged appropriately when their knowledge raised [6]. Also satisfied employees show more commitment to their companies and higher performance [7].
The aim of this research is to find the relationship between independent variables and dependent variable and if the relation confirm, then to assess to what extent each variable affects the employees to be engaged emotionally and physically in the new practices and procedures suggested by the company. The study focuses on middle management level in factories located in Nablus.

Middle management has the most effect on the change application according to the plant manager of National Company for Carton Industry and research and development manager of Al-Hijjawi Company for Paper Industry, both located in Nablus.

Reviewing similar studies shows that no same group of factors used in this research were examined for the same research, and no similar studies were conducted for factories in Nablus region, especially for medium managerial level. The gap in the literature mainly presented in studying a group of factors for all hierarchical level with no specific studies were conducting for small to medium factories, also no similar studies were conducted in the same region of this research.

Specifically, the research model assessing the question: What factors affecting employee's responses to change in Nablus' industrial factories? Through examining the significant effect of the three independent variables mentioned lately.

This study is quantitative and data will be collected by distributing

*Corresponding author: Shuqqo $\mathrm{H}$, Department of Industrial Engineering, AnNajah National University, Nablus, Palestine, Israel, Tel: 00970595031336; E-mail: hana_shuqqo@hotmail.com

Recieved May 18, 2017; Accepted June 15, 2018; Published June 22, 2018

Citation: Shuqqo H, Ghanayem F (2018) Factors Affecting Employees' Responses to Change in Nablus Industrial Factories. J Entrepren Organiz Manag 7: 240. doi: 10.4172/2169-026X.1000240

Copyright: @ 2018 Shuqqo $\mathrm{H}$, et al. This is an open-access article distributed under the terms of the Creative Commons Attribution License, which permits unrestricted use, distribution, and reproduction in any medium, provided the original author and source are credited. 
a written questionnaire. For analysis PLS-SEM software will be used to find the results based on the collected data.

The following sections of the research are: Section 2 provides the literature review of similar studies. Section 3 proposes the conceptual model of the research and suggested hypothesis. Section 4 explains the method used in data collection. Section 5 explains the data analysis and discussion of the results found. Section 6 provides the conclusion of the results and recommendations.

\section{Literature Review}

Change has strongly become tendency of the organizational life rather than an alternative that they can choose. As affirmed by Goncalves and Goncalves [8] companies have strongly faced an environment full of changes and increasingly variable. The change has increasingly become a necessity for organizations; even the most successful companies have to face necessity of change [9].

As globalization become more prevalent and facing development in technology that allow organization to learn more, more quickly, than ever before, many companies are continually evolving their business practices with changing. Haleem [10] also analyzed in his study that there a number of change drivers that force to accelerate speed of change. These factors include advancing technology and development, economic resources and cultural diversity. Frequent effective nature of business environment also influences customer's demand and preferences on all kinds of products and services and therefore, being able to cover these demands needs organization research and leading development new strategies and policies [9].

According to an article published by Hultman [11], change can be defined as doing things new or in different way from what they were before. The only thing permanent in the business world is change. As asserted by Armstrong [12], changes the only thing that remains constant in organizations. Organizational change is needed for a company to stay competitive, to succeed in today's market place; to maintain relevant and profitable. Baulcomb [13] in his study emphasized that change would further provide an effective opportunity to move the current state to right direction and forward in preparation for the trusted proposed plans.

In these days, the hardest challenge for organizational leaders is to manage new changes. With doubling knowledge and advanced technology every year, leaders face toughest pressure with trying to gain support for change [11]. Leading and managing change during emerging and transition phase is the most critical state in the change processes, this stems from different problems may face. These can include low stability, misdirected energy, loss momentum, conflict and resistance to change [12].

Organization is robustly trying to get their needed results through people. As people running the tasks, controlling activities and process, they are extremely important for the company to succeed, and for this reason a special attention should be given for human factor and its development in the contemporary companies [8].

Dent and Goldberg [14] gave the idea that the key to start an organizational change is with the understandings and attitudes of individuals. As according to Haleem [10], organizational change management activities involve defining employees' behaviors, attitudes and new values.

Change is not innovation idea until it is implemented and this is does not happen without passion and trust, these are not the goals but they are the engines, passion fuels performance, and if the resistance is equal to or greater than any of these two, change will not occur.

Woodward and Hendry [15] analyzed that in a changing workplace, employees are continually evaluating what is going on and what is its significance for them. Human beings naturally want to be involved in every culture; some employees are frustrated with trying to get some of their employers to adopt new ways of doing things. As asserted by Hultman [11] understanding people's beliefs, facts and values is needed to find the causes of their resistance.

Resistance to change is a daunting challenge for people throughout lives. When talking about resistance, which usually refer to behaviors observed in others, it common to hear someone say, "He is refusing new procedures," or "She is resisting going along with these new changes"[11]. As enhanced by Dent and Goldberg [14], change resistance is a psychological phrase sited within each individual, and the manger's task to overcome it as possible. also according to other article [8], the level of resistance of an individual is determined by how much he recognize the new changes," It's a good or bad thing?", and also how will be the change on him.

However, some people will welcome the new changes as an opportunity; this group of people is required to help in merging and introducing the change as change agent [12]. Baulcomb [13] recommended when any individual accept new change and willing to try it, this will influence the rest of team.

Yet, a large number of change programs still appear to fail or will fail, and the resistant individuals are the most common reasons for change failure [16].

"Leading to employees' response to change" is a framework that can utilize as effective tool to guide actions toward the right direction. As according to an article published by Dent and Goldberg [14], for change process to be effective, any resistance that may occur should be foreseen and neutralize, and the greatest need for change process is the manger to overcome resistance. Therefore, this study addresses important research issue and explore research question of what factors affecting employees' responses to organizational change, and how these responses can be enhanced.

Various factors are responsible for driving the employees' resistance that hinders the change process. First, lack of awareness and recognition of change and its importance, lack of incentives that motivate people and positively affect each work output. In addition, Employee dissatisfaction during change in the workplace.

\section{The Conceptual Model and Hypotheses}

\section{Conceptualization of the proposed model}

The proposed model in Figure 1 consists of four constructs: awareness, incentives, employees' satisfaction and employees' responses to change. These constructs are presumed to have reflective indicators. As shown in Table 1, the indicators used in this study were developed based on previous studies.

Awareness: Individuals' awareness of working environment issues is an important first step in the decision making process [17]. This study uses the following measurements scales to measure awareness:

Structured training: According to an article published by Armstrong [18], training is planned application with formal activities to impart new knowledge and new skills necessary to increasing awareness of any changing in the work environment. It important to 


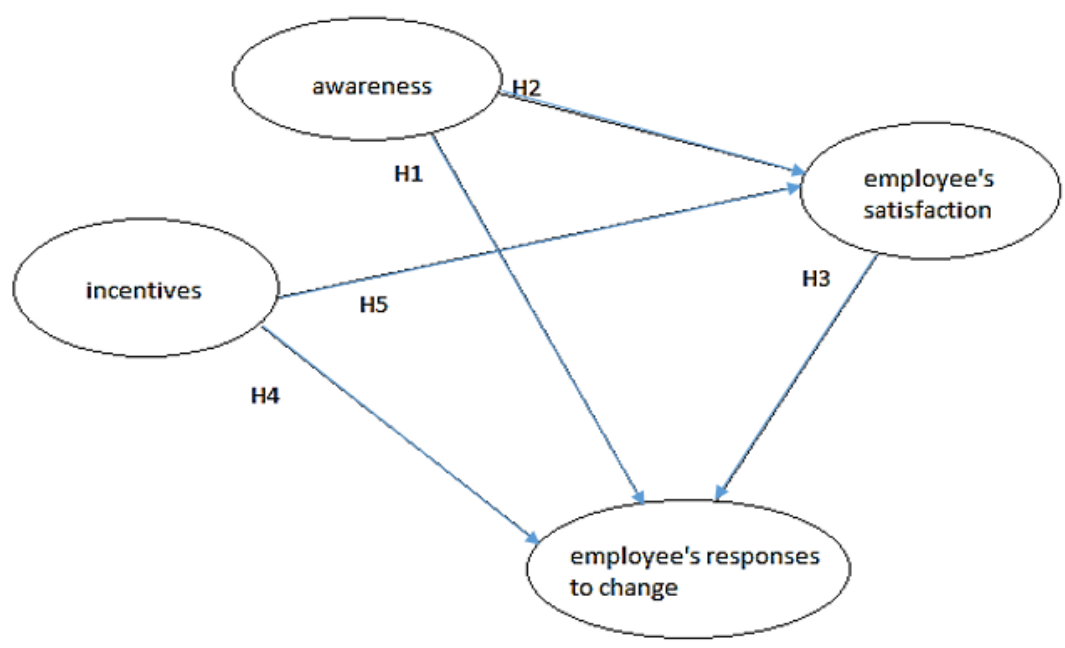

Figure 1: The conceptual model and proposed hypotheses.

\begin{tabular}{|c|c|c|}
\hline S No. & Indicator & Based on references \\
\hline 1. & Structured training & Armstrong [18], Haleem [10], Anan and Ressang [6] \\
\hline 2. & Persuading strategies & Marker [19] \\
\hline 3. & Knowledge growth & Charttman [11], Anan and Ressang [6] \\
\hline 4. & Performance and Efficiency & Yareness \\
\hline 5. & Commitment & Coppens et al. [25], Anan and Ressang [6] \\
\hline 6. & Improved skills & Hultman [11] \\
\hline 7. & Rewards & Epstein and Ward [20], Van et al. [21] \\
\hline 8. & Promotions and career movements & Lee [22] \\
\hline 9. & Contracts for job security & Charity Tinofirei [5] \\
\hline 10. & Developing relationships & Haleem [10] \\
\hline 11. & Improved service quality & Dent and Goldberg [14] \\
\hline 12. & Achieved goals & Haleem [10] \\
\hline 13. & Profitability & Employes \\
\hline
\end{tabular}

Table 1: Establishment of conceptual model constructs.

note that training for new change's process and enabling environment to employee, where they can preparing for desired skills and required knowledge is a continuous procedures during changes, especially in the early phases [10]. Therefore, if the companies neglect the structured training side, it may not provide full understanding and awareness of its staff regarding the company's new activities and changes [6].

Persuading strategies: The need to understand and recognize the new changes and its importance can be justified for employees by addressing personal concerns first, and linking it to other issues that individuals care about, for example Health and safety benefits [19].

Individual knowledge growth: We live in an age when employees expect to have their view considered. Therefore, employees should be asked if they will be affected by the change and learned from the experiences with the new changes [11]. Also, as according to Adnan and Ressang [6], education and increasing knowledge help to improve understanding and Realizing all new in workplace.

Incentives: Incentives are strategies, policies and practices required to ensure that the value of people and the contribution they make to achieving organizational, departmental and team goals is recognized and rewarded [18]. As asserted by Tinofirei [5], when employees are motivated, their work outputs despite any environments changes may be affected positively. Hence, this study uses the following measurement scales to measure the incentives.
Reward: When initiating change, it's important to identify rewards related to employees' values money, benefits, and new opportunities. Therefore, people will be much more encouraged to support the new changes and help make it work properly, if there's something in it related for them [11].

Promotion: One of the main reasons for employees to increase effort on the job is to prove their worth for a promotions and career movements [20]. Also promotions can be a substitute for incentive compensation as a way of giving incentives [21].

Contracts for job security: Employment security refers to providing a regular and permanent job position to employees rather than shortterm contracts, these permanent contracts signal an organization's commitment to employee, which in turn plays an important factor as an effective incentive [22].

Employees' satisfaction: Presently there are many factors contributing to job satisfaction, especially as it expected to lead toward better work performance, higher commitment from workers and effective improved skills [23]. Hence, this study uses the following measurement scales to measure the employees' satisfaction.

Performance and efficiency: Employee performance is the successful tasks accomplishment by a chosen individual or group of individuals, as set and measured by a supervisor or manager, to pre- 
defined acceptable standards while effectively using of resources with a changing environment [5].

During resistance, people try to keep holding on ordinary ways of doing things, they feel worse, stress is higher, they lose control and performance is at lower level, and therefore companies must constantly seek to improve their employees' satisfaction [24].

Commitment: Employees, who indicated their organization as effective company, will be more committed their organization and more satisfied with their careers [7].

Improved skills: As Coppens et al. [25] and Adnan and Ressang [6] analyzed in their studies that, Training and education are showing the strongest enhancement in attitudes, knowledge, and skills. Improving skills consider simply way to boost employees' satisfaction.

Employees' response to change: Implementing change programs has never been an easy task because the process has always full of change barriers. One of the reasons for this difficulty has been the individuals' resistant behaviors. They may have different reasons for these behaviors [9]. Hence, this study uses the following measurement scales to measure employees' responses to change.

Developing relationships: Employee/employer relationship must have benefits for both sides. Both will better understand each other's needs by effectively communicating and ensuring that decisions made are largely for the benefit of the organization as well as the employees [5], and which in turn improve employees' responses to any new decisions and changes.

Improve service quality: The new system and process which are adopted should be closely linked with the strategy. It mean that these changes should be systematic, organized and well implemented, which in turn lead to improve the quality of product and services [10].

Achieved goals: "Leading to employees' response to change" is a framework that can utilize as effective tool to guide actions toward the right direction. As according to an article published by Dent and Goldberg [14], for change process to be effective, any resistance that may occur should be foreseen and neutralize and the employees' responses should be increased.

Profitability: The incentives and benefits are not the only primary motivation for employees to work. There are many other sources of meaning and motivation for employees to work. These sources of motivation have an effective impact at the company/shareholder (e.g., profitability and sales), Business growth can be achieved by maintain employees' responses for the new changes. Trust of clients is achieved and thus the business is run towards profit [10].

\section{Hypothesis development}

After reviewing similar researches, five hypotheses are extracted to establish the model's constructs as shown in Figure 1. The development of the proposed hypotheses is following the mentioned logic:

Multiple factors were found that contributed to rapidly evolving working environments, which influence the level of need and job satisfaction of working employees, for example motivational rewards and incentives, individuals knowledge growth and structured training which may conclude as the understanding and awareness of the working environments [23].

Also they analyzed in their study generous rewards; compensation, benefits, structured training and satisfaction through income tend to retain people, lead to high satisfaction, commitment, and loyalty. Hence, two hypotheses (H2 and $\mathrm{H} 5)$ are:

H2: Awareness positively affects employees' satisfaction.

H5: Incentives positively affects employees' satisfaction.

Implementing change programs has never been an easy task because the process has always full of change barriers. One of the reasons for this difficulty has been the individuals' resistant behaviors. They may have different reasons for these behaviors [9]. Various factors are responsible for driving the employees' resistance that hinders the change process. First, lack of awareness and recognition of change and its importance, lack of incentives that motivate people and positively affect each work output. In addition, employee dissatisfaction during change in the workplace. Hence, three hypotheses (H1, H3 and H4) are:

H1: Awareness positively affects employees' responses to change.

H3: Employees' satisfaction positively affects employees' responses to change.

H4: Incentives positively affects employees' responses to change.

\section{Research Methodology}

\section{Survey design and instrumentation}

A written survey was designed to examine the proposed hypothesis of the research conceptual model. The questionnaire involved two main sections. The first section contains five demographical questions; questions one and five are continuous scale and questions two to four are categorical. The second section contains thirty-four questions, thirty-one of them are measured by five point Likert scale and other two questions are categorical. These questions were developed based on comprehensive literature review. In total, the survey contains 39 different questions.

\section{Sampling}

The survey of the research were conducted on thirteen factory located in Nablus area. The unit of analysis for this study is the managerial staff excluding the top management level, the possible positions for targeted unit of analysis could be: plant manager, sales manager, production manager, maintenance manager, research and development manager, human resource manager and supervisor. A total of 163 questionnaires were sent to the factories, 149 of the cases responses with a response rate of $91.41 \%$, the valid cases are 132 resulting in $88.59 \%$ effective response rate [26], this level is exceeding the $70 \%$ response rate which considered to be very good [27]. The survey was conducted through one week.

The research conceptual model shown in Figure 1 will be analyzed according to the obtained valid cases. For the 132 sample size, $G^{*}$ power 3.1.9.2 software was used to determine the power of the research, with 0.12 coefficient of determination value resulted after analyzing the model by PLS-SEM, and significance level of 0.05 , the Post hoc power analysis resulting a power of $99 \%$ for the research.

\section{Results and Analysis}

The research's conceptual model is examined by PLS-SEM for its reliability and validity of measurement model, also the structural model is tested for its significance and overall fitting. Partial least square structural equation modelling (PLS-SEM), known as SEM is a 
path modelling software based on variance with a purpose of increasing the variance explained by the independent variables without the assumption that the data are normal, it also attain adequate statistical power with small sample size, this application is exceedingly used by social science researchers since its inception [28].

Sample size is considered small if lower than 150 cases [29], and since the valid sample for this research is 132 cases, the PLS-SEM is used to analyze the data at two stages: (1) assessing the measurement model by testing the reliability and validity of the model's constructs; (2) assessing the structural model by testing the path coefficient of proposed hypotheses and its significance. The data set are analyzed by The Smart PLS 3 software.

\section{Assessing measurement model}

Reliability and validity tests are required for assessing reflective measurement model before analyzing the structural model [30]. The purpose of these tests is to assess the internal consistency of the values recorded by respondents for the research questionnaire by examining each variable versus its related indicator's values, and the validity of the questionnaire's questions.

The model at first stage is tested for its internal consistency using the Cronbach's alpha test and composite reliability. Cronbach's alpha is a measure for assessing the internal consistency of the construct's indicators [31]. Acceptable values ranges between 0.6 and 0.7 [32]. Hair et al. [33] also confirm that values between 0.6 and 0.7 considered acceptable for exploratory research, but values above 0.708 is preferred, and since this test has its limitations and it assumes that all the outer loading of the construct have the same value and depends on the number of the indicators and their correlations, the composite reliability test is recommended to be used beside the Cronbach's alpha test. According to Table 2, all Cronbach's alpha values are above the preferred value 0.708 as follow: employee's responses to change ( $\alpha=0.751$ ), employee's satisfaction $(\alpha=0.718)$ and incentives $(\alpha=0.808)$, except one construct 'awareness' with acceptable value of ( $\alpha=0.647)$, as a result, the proposed constructs of conceptual model considered to be reliable for their indicator's internal consistency.

Additional test for the internal consistency called the composite reliability is conducted to ensure the measurement model assessing procedure, this test is considered to be more accurate because it does not assume that all values of indicators are equal in their reliability, it also assigns reliability values due to the priority when estimating the model algorithm, for that the test is considered more suitable for SEM [34], with a recommended threshold value of 0.7 [35]. As shown in Table 2, the composite reliability values are above 0.7 for the constructs: employee's responses to change (0.843), employee's satisfaction (0.814), incentives (0.882) and awareness (0.803), and thus all constructs are considered reliable.

Next, the model is analyzed for measurement's validity. It is important to insure that validity test is verified to consider constructs as trustworthy measures [36]. The convergent validity and discriminant validity tests are used to assess the validity of the construct and its related indicators in the measurement model. Convergent validity is a measure used to explain to what extent is the positively strength relations of construct's indicators are hold together [37]. Average variance extracted (AVE) is used to compute the convergent validity, with a value of 0.5 and above indicates adequate level of convergent validity thus means that the construct are explaining at least 50\% of its indicator's variance [34]. According to Table 2, the convergent validity test indicates the AVE values of the constructs as follow: employee's responses to change (AVE $=0.574)$, employee's satisfaction ( $\mathrm{AVE}=0.597)$, incentives $(\mathrm{AVE}=0.715)$ and awareness (AVE $=0.579$ ), as a result the test is validated.

Discriminant validity is a measure for testing the extent to which the construct's indicators correlate with other indicators in the conceptual model [38]. Discriminant validity is assessed by FornellLarcker and cross-loadings, these measurements are conducted by computing the square root of $\mathrm{A} V \mathrm{VE}$ for each construct, then comparing the resulted values with other construct's correlations to ensure that it has the biggest value among others [33]. Previewing Table 3, all computed square root values for construct's AVE are higher than other correlations values, thus emphasizes the discriminant validity.

The Heterotrait-Monotrait ratio of correlation (HTMT) is a new approach used to double check the validity of the constructs, and considered to be preferable over other discriminant validity tests due to its sensitivity [39]. HTMT is based on correlation and average calculations, by computing the average of the correlations between constructs, the central tendency of the average of the correlations within indicators for each construct, and finally the ratio between the average and central tendency, and for that is considered appropriate for variance-based SEM [40], considering a value of 0.9 as a maximum threshold value validity [41]. As shown in Table 4, all the values are below the to confirm the discriminant critical threshold, consequently the test is confirmed.

Estimation of measurement model, also called outer model is summarized in Table 5. This includes examining the outer loadings assigned to each indicator and their significance t-values. The outer loadings are obtained through calculating the PLS Algorithm with a threshold value of 0.7 or higher [42], however, values less than 0.7 are accepted if the indicator is recently established, but values below 0.4 should be eliminated [43]. According to Table 5, all the indicator's

\begin{tabular}{|c|c|c|c|c|c|}
\hline S No. & Construct & $\mathbf{R}^{2}$ & Cronbach's Alpha ( $\alpha$ ) & Composite Reliability & AVE \\
\hline 1. & Employees' responses to change & 0.12 & 0.751 & 0.843 & 0.574 \\
\hline 2. & Employees' satisfaction & 0.07 & 0.718 & 0.814 & 0.597 \\
\hline 3. & Incentives & & 0.808 & 0.882 & 0.715 \\
\hline 4. & Awareness & & 0.647 & 0.803 & 0.579 \\
\hline
\end{tabular}

Table 2: Reliability and validity analysis.

\begin{tabular}{|c|c|c|c|}
\hline S No. & Construct & $\mathbf{1}$ & $\mathbf{2}$ \\
\hline 1 & Awareness & 0.761 & \\
\hline 2 & Employees' responses to change & 0.260 & 0.757 \\
\hline 3 & Employees' satisfaction & 0.177 & 0.098 \\
\hline 4 & Incentives & 0.002 & 0.773 \\
\hline
\end{tabular}

Table 3: Discriminant validity analysis ( AVE is inserted diagonally). 


\begin{tabular}{|c|c|c|c|}
\hline S No. & Construct & $\mathbf{1}$ & $\mathbf{2}$ \\
\hline 1 & Awareness & & \\
\hline 2 & Employees' responses to change & 0.345 & \\
\hline 3 & Employees' satisfaction & 0.226 & \\
\hline 4 & Incentives & 0.163 & 0.121 \\
\hline
\end{tabular}

Table 4: Discriminant validity analysis (HTMT).

\begin{tabular}{|c|c|c|c|}
\hline \multirow[t]{2}{*}{ S No. } & \multirow[t]{2}{*}{ Constructs and indicators } & \multicolumn{2}{|c|}{ Outer loadings } \\
\hline & & Point estimation & t-values \\
\hline \multirow[t]{5}{*}{1.} & Employees' responses to change & & \\
\hline & achieved goals & 0.834 & 15.85 \\
\hline & developing relationships & 0.690 & 5.635 \\
\hline & improve service's quality & 0.757 & 10.334 \\
\hline & profitability & 0.741 & 10.202 \\
\hline \multirow[t]{4}{*}{2.} & Employees' satisfaction & & \\
\hline & commitment & 0.742 & 3.718 \\
\hline & improved skills & 0.901 & 8.292 \\
\hline & performance & 0.656 & 3.006 \\
\hline \multirow[t]{4}{*}{3.} & Incentives & & \\
\hline & job security contracts & 0.807 & 5.271 \\
\hline & promotions & 0.917 & 10.804 \\
\hline & rewards & 0.808 & 8.267 \\
\hline \multirow[t]{4}{*}{4.} & Awareness & & \\
\hline & knowledge growth & 0.672 & 4.481 \\
\hline & persuading strategies & 0.736 & 5.611 \\
\hline & structured training & 0.862 & 14.434 \\
\hline
\end{tabular}

Table 5: Analysis of measurement model.

outer loadings are above 0.7 , except three indicators with values of $(0.690,0.656$ and 0.672$)$, are very close to the preferred threshold value 0.7 and above the acceptable value 0.4 . Thus, the measurement model considered to be reliable.

The loading values emphasizes that the indicators are correctly assigned to their suggested constructs. In addition, $t$-values are checked to insure the significance of outer loadings. If the $t$-values are more than 1.96 , the loadings are highly significance [44]. As mentioned in Table 5, all loadings are above the threshold value, and thus significance.

\section{Assessing structural model}

The coefficient of determination $\left(\mathrm{R}^{2}\right)$ is a statistical value explains the variance in the endogenous construct explained by all exogenous constructs with value ranges between 0 and 1 , this value tends to be low in human behavior studies often of 0.2 to 0.1 , the logic behind these low values attributes to the unpredictable and inexpressible in human behavior $[45,46]$. According to Figure 2 the $\mathrm{R}^{2}$ value for this research model is 0.12 , denotes that $12 \%$ of the variance in the employee's responses to change dependent variable can be explained by the three independent variables 'awareness', 'incentives' and 'employee's satisfaction'. The structural model implies that 'awareness' has the biggest effect on employee's responses to change with a value of 0.258 , then 'incentives' and 'employee's satisfaction' with values of 0.227 and 0.007 respectively.

Verifying the path coefficients values and significance of the relationship between the constructs in the structural model is essential to evaluate the proposed hypotheses. To verify the mentioned statistics, standardized path coefficient (B-value) should be at least 0.1 or above to explain the relation correctly [47], while Topor [48] mentioned in his book that B-value ranges between +1 and -1 with strong and positive relationship when values approaches +1 , also the same concept is considered for negative values, with a corresponding t-value above 1.96 or below -1.96 considered significance at 0.05 level [44]. PLSSEM is used to calculate the bootstrapping procedure with its default settings required to obtain the $t$-values [33]. The resulting $t$-values are illustrated in Figure 3.

As presented in Table 6, the corresponding t-value and P-value for B-value determine the significance of the supposed relationship between constructs in the structural model. The resulting values affirm that 'awareness' has a positive and significance effect on 'employee's responses to change', given $(B=0.258)$ and $(t=2.807)$, and it has a positive effect on 'employee's satisfaction' with $(B=0.176)$ but not significance because the $t$-value 1.671 is less than 1.96 . Also, the results affirm that 'employee's satisfaction' has a positive but small effect on 'employee's responses to change' with $(\mathrm{B}=0.007)$ and not significance with $\mathrm{t}$-value 0.057 below the threshold level. Whereas the results of 'incentives' affirm that it has a positive and significance effect on both 'employee's responses to change' with $(B=0.227)$ and $(t=2.322)$, and 'employee's satisfaction' with $(\mathrm{B}=0.197)$ and $(\mathrm{t}=2.035)$.

Considering the above results analyzed for the proposed structural model, the model confirm that both 'awareness' and 'incentives' are a significance predictors for 'employee's responses to change' but does not confirm that 'employee's satisfaction' predict 'employee's responses to change'.

Previewing the resulting values mentioned in Table 6, the results emphasize that $\mathrm{H} 1, \mathrm{H} 4$ and $\mathrm{H} 5$ are confirmed. Whereas $\mathrm{H} 2$ and $\mathrm{H} 3$ are not confirmed.

According to the resulted hypotheses, a recent justification conclude that, although the common belief among managers that employees' satisfaction can lead to better performance and engagement with companies' practices, but in fact researchers found a weak relationship 


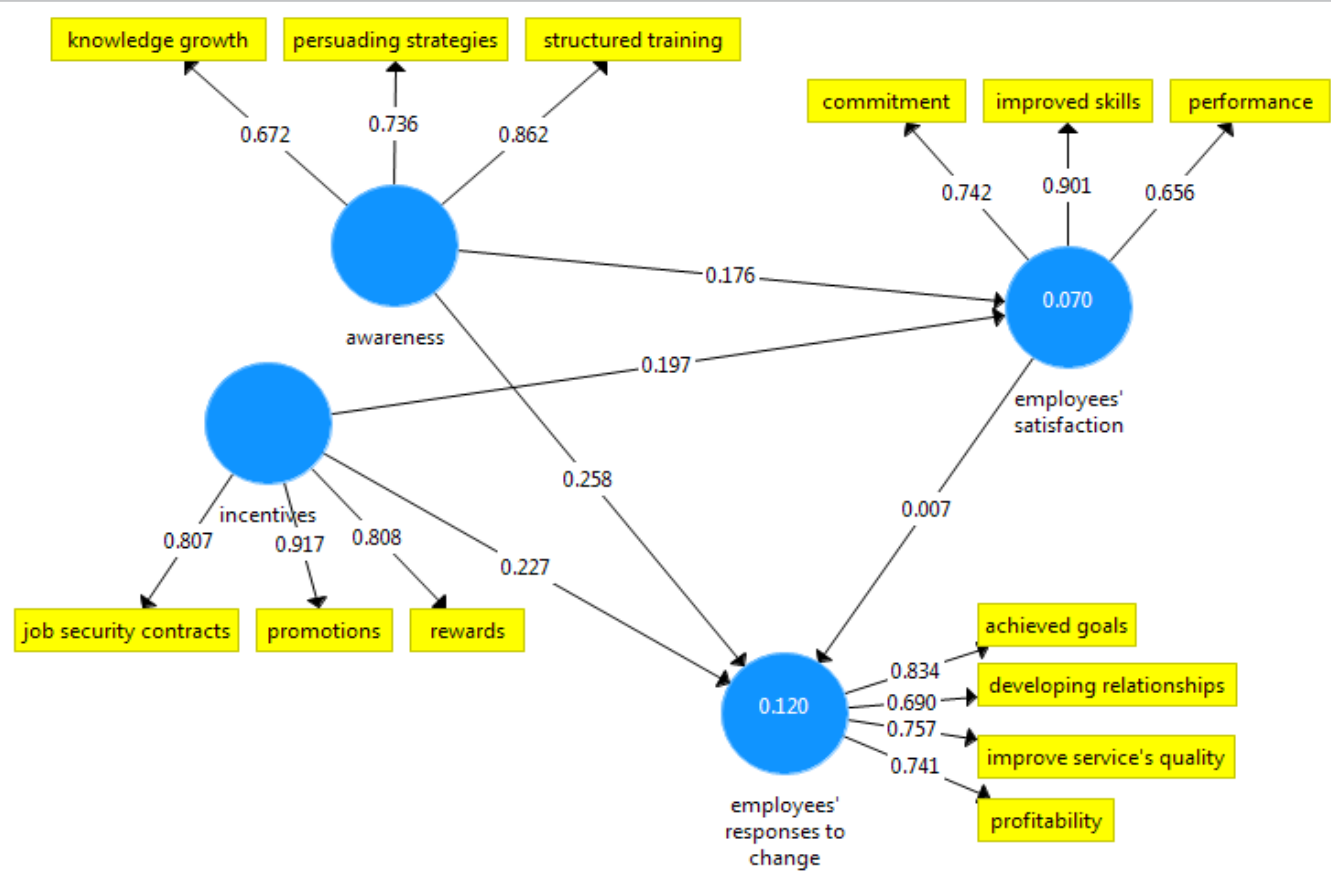

Figure 2: Path modelling assessment of research conceptual model.

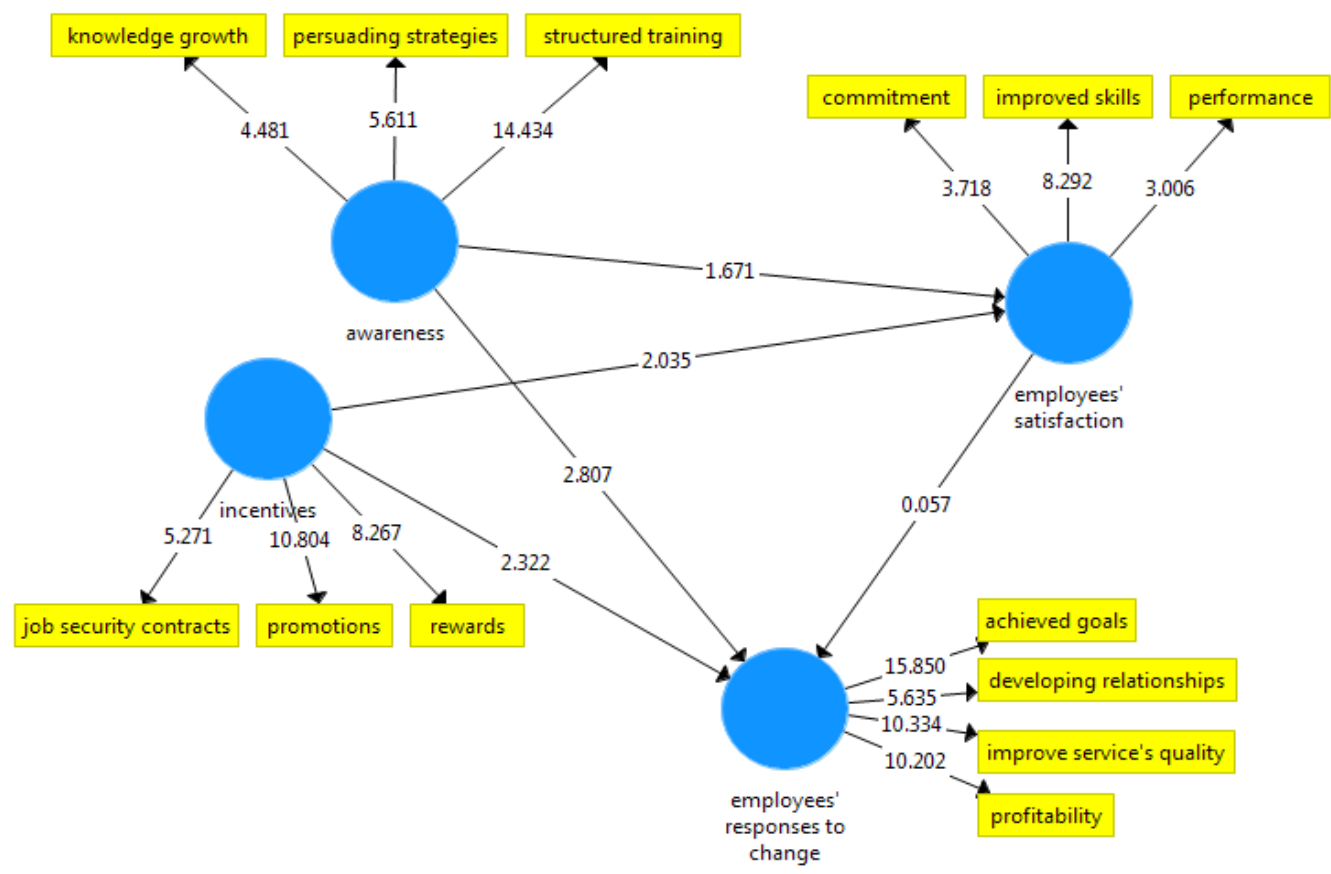

Figure 3: Model fit assessment of research conceptual model.

and suggest that it is highly influenced by other conditions [49].

Also, Employee awareness can be specified as the information quality for work system and practices. Abraham et al. [50] justified in their study the weak relationship between employees' satisfaction and their awareness and understanding of different practices in the working environment, they conclude that employees who are less satisfied with their current systems are more likely to understand and realize the new work systems.
In addition, the analysis of the structural model presented only $7 \%$ of variance explained in 'employees' satisfaction' by 'awareness' and 'incentives'. These results considered to be important especially for managers who are willing to understand their subordinates. Therefore proposing additional future studies and indicators to understand the factors leading to employees' satisfaction.

\section{Conclusion and Recommendation}

The aim of this study is to explore the unique factors that affect 


\begin{tabular}{|c|c|c|c|c|c|c|}
\hline \multirow[t]{2}{*}{ S No. } & \multirow[t]{2}{*}{ Proposed path model } & \multirow[t]{2}{*}{ B-value } & \multirow[t]{2}{*}{ STDEV } & \multicolumn{2}{|c|}{ Significance } & \multirow[t]{2}{*}{ Result } \\
\hline & & & & t-value & P-value & \\
\hline 1. & Awareness employee's responses to change & 0.258 & 0.092 & 2.807 & 0.005 & $\mathrm{H} 1$ is confirming \\
\hline 2. & Awareness employee's satisfaction & 0.176 & 0.105 & 1.671 & 0.095 & $\mathrm{H} 2$ is not confirming \\
\hline 3. & $\begin{array}{l}\text { Employee's satisfaction employee's responses to } \\
\text { change }\end{array}$ & 0.007 & 0.124 & 0.057 & 0.955 & $\mathrm{H} 3$ is not confirming \\
\hline 4. & Incentives employee's responses to change & 0.227 & 0.098 & 2.322 & 0.021 & $\mathrm{H} 4$ is confirming \\
\hline 5. & Incentives employee's satisfaction & 0.197 & 0.097 & 2.035 & 0.042 & $\mathrm{H} 5$ is confirming \\
\hline
\end{tabular}

Table 6: Analysis of structural model.

employees' responses to change in industrial factories of Nablus city. Employees' resistance to change is supposed to be one of the most important factors affecting the overall change process in organizations. The analyzed data of the research model emphasized the effect of awareness and incentives on employees' responses to change. Assessing those factors confirmed that knowledge growth, persuading strategies and structured training are significance indicators of employees' responses to change with loading values of $0.672,0.736$ and 0.862 respectively. Conducting such practices can lead employees to engage effectively in organization polices and goals. Whereas those indicators cannot predict the employees' satisfaction as the path coefficient is not significance. The analysis also confirmed the effect of job security contracts, promotions and rewards on both employees' satisfaction and employees' responses to change with loading values of $0.807,0.917$ and 0.808 respectively.

As an unexpected result, the analysis does not confirm the effect of employees' satisfaction on employees' responses to change. While commitment, improved skills and performance are reliable indicator of employees' satisfaction with loading values of $0.742,0.901$ and 0.656 respectively, they do not affect the employees' responses to change because of low value of path coefficient.

According to the relationships confirmed by SEM analysis, that factors affecting employees' responses to change at Nablus industrial factories can positively affect the employees' responses to change. Consequently, managers are advised to consider the following recommendations: First, managers should provide more attention for establishing a systematic training program that complies with their new changes. In addition, they have to conduct reward and promotion system to get their employees involved in the new plans. Finally, they should be aware in retaining the employees in secure to maintain the trust to ensure their engagement regardless of the change to be applied.

Whereas the analysis does not confirm the relationship between employees' satisfaction and employees' responses to change, that suggest further studies including possible confounding variables and other possible conditions affecting this relation.

\section{References}

1. Markos S, Sridevi MS (2010) Employee Engagement: The Key to Improving Performance. Int J Bus Manag 5: 89.

2. Pandit S, Jain J (2012) Resistance to change. Review of HRM 1: 89-96.

3. Thao LTT, Hwang CJ (2010) Factors Affecting Employee Performance Evidence from Petro Vietnam Engineering Consultancy JSC.

4. Saeed R, Mussawar S, Lodhi RN, Iqbal A, Nayab HH, et al. (2013) Factors Affecting the Performance of Employees at Work Place in the Banking Sector of Pakistan. Middle East J Sci Res 17: 1200-1208.

5. Tinofirei C (2011) The Unique Factors Affecting Employee Performance In Non Profit Organizations.

6. Adnan NH, Ressang A (2014) Ergonomics Awareness on Construction Site.

7. Yap M, Holmes M, Ann C, Cukier W (2015) Article information. Journal of Service Management 26: 182-205.
8. Goncalves JM, Goncalves RPDS (2012) Overcoming Resistance to Changes in Information Technology Organizations. Procedia Technology 5: 293-301.

9. Kebapci S, Erkal H (2009) Resistance to change.

10. Haleem F (2015) Planning change in an organization; MCB bank limited, Pakistan. Journal of Central Banking Theory and Practice 4: 75-107.

11. Hultman K (2014) Managing resistance to change 3: 693-705.

12. Armstrong M, Stephen T (2009) Armstrong' S Handbook of Human Resource Management Practice.

13. Baulcomb JS (2003) Management of change through force field analysis. J Nurs Manag 11: 275-280.

14. Dent EB, Goldberg SG (1999) Challenging resistance to change. J Appl Behav Sci 35: 25-41.

15. Woodward S, Hendry C (2004) Leading and coping with change. Journal of Change Management 4: 155-183.

16. Griffith J (2001) Why change management fails. Journal of Change Management 2: 297-304

17. Butterfield KD, Trevin LK, Weaver GR (2000) Moral awareness in business organizations: influences so issue-related and social context factors. Hum Relat J 53: 981-1018.

18. Armstrong M (2014) A handbook of human resource management practice. Hum Resour Manage.

19. Marker A (2009) 10 Strategies You Can Use to Overcome Resistance to Change.

20. Epstein GS, Ward ME (2006) Perceived income, promotion and incentive effects. Int J Manpow 27: 104-125.

21. Herpen Van M, Cools K, Praag Van M (2006) Wage structure and the incentive effects of promotions. Kyklos 59: 441-459.

22. Lee KJ (2018) Strategic human resource management for universityindustry collaborations in Korea: financial incentives for academic faculty and employment security of industry liaison offices. Technol Anal Strateg 30: 461-472.

23. Mansor N, Munirah M, Nik N (2012) Job satisfaction among the bankers: An investigation on Islamic financial institution in eastern region of Malaysia. Asian Soc Sci 8: 186-197.

24. Washington M, Hacker M (2005) Why change fails: knowledge counts. Leadership Org Dev J 26: 400-411.

25. Coppens E, Audenhove C, Van Purebl G, Szekely A, Koburger N, et al. (2017) Author's Accepted Manuscript skills towards depression. J Affect Disord.

26. Yu J, Sujian G (2012) Civil Society and Governance in China. Springer.

27. Rubin A, Babbie ER (2009) Research Methods for Social Work. Cengage Learning.

28. Afthanorhan WMABW (2013) A comparison of partial least square structural equation modeling (PLS-SEM) and covariance based structural equation modeling (CB-SEM) for confirmatory factor analysis. IJESIT 2: 198-205.

29. Pallant J (2011) SPSS Survival Manual. Open University Press, p: 359.

30. Codita R (2011) Testing the contingency model of marketing-mix standardization and Its Performance Outcomes. Contingency Factors of Marketing-Mix Standardization pp: 136-206.

31. Rutkowski L, Davier M von, Rutkowski D (2013) Estimating reliability. In: Leslie Rutkowski DR, Matthias von Davier editor. Handbook of International LargeScale Assessment, pp: 647 pages. CRC Press. 
Citation: Shuqqo H, Ghanayem F (2018) Factors Affecting Employees' Responses to Change in Nablus Industrial Factories. J Entrepren Organiz Manag 7: 240. doi: 10.4172/2169-026X.1000240

Page 9 of 9

32. Tsang P, Cheung SKS, Lee VSK, Ronghuai H (2010) Research methodology. In: Philip Tsang RH, Cheung SKS, Lee VSK editors. Hybrid Learning, p: 534, Springer Science \& Business Media.

33. Hair JFJ, Hult GTM, Ringle C, Sarstedt M (2014) A Primer on Partial Least Squares Structural Equation Modeling (PLS-SEM). Long Range Planning.

34. Hair JF, Ringle CM, Sarstedt M (2011) PLS-SEM: Indeed a Silver Bullet. J Market Theor Pract 19: 139-152.

35. Siponen M, Mahmood MA, Pahnila S (2014) Employees' adherence to information security policies: An exploratory field study. Journal Information and Management 51: 217-224.

36. Morizot J (2014) Construct Validity of Adolescents' Self-Reported Big Five Personality Traits: Importance of Conceptual Breadth and Initial Validation of a Short Measure. Assessment 21: 580-606.

37. Dmitrienko A, Chuang-Stein C, D'Agostino RB (2007) Pharmaceutical Statistics Using SAS: A Practical Guide. SAS Institute.

38. Dwaikat NY, Money AH, Behashti HM, Salehi-Sangari E (2018) How does information sharing affect first-tier suppliers' flexibility? Evidence from the automotive industry in Sweden. Prod Plan Control 29: 289-300.

39. Henseler J, Ringle CM, Sarstedt M (2014) A new criterion for assessing discriminant validity in variance-based structural equation modeling. J Acad Market Sci 43: 115-135.

40. Voorhees CM, Brady MK, Calantone R, Ramirez E (2016) Discriminant validity testing in marketing: an analysis, causes for concern, and proposed remedies. J Acad Market Sci 44: 119-134.
41. Alcaide-Munoz L, Alcaraz-Quiles JF (2018) Optimizing E-Participation Initiatives through Social Media. IGI Global.

42. Thomas H (2018) Intracranial Pressure \& Neuromonitoring XVI. Springer.

43. Hulland J (2014) Use of partial least squares (PLS) in strategic management research: A review of four recent studies 20: 195-204.

44. Lorna U, Hericko M, Ting IH (2015) An empirical study of the effect of SCM practice on corporate performance. In: Uden I-HTL, Heričko M editors. Knowledge Management in Organizations, p. 128, Springer, 2015.

45. Laura L, Felbinger C (2006) Interpreting multiple regression output. In Public Program Evaluation: A Statistical Guide. ME Sharpe 2006.

46. Chatterjee S, Singh NP, Goyal DP, Gupta N (2014) Managing in Recovering Markets. Springer.

47. Moser R (2007) Strategic Purchasing and Supply Management: A StrategyBased Selection of Suppliers. Springer Science \& Business Media.

48. Topor FS (2016) Handbook of Research on Individualism and Identity in the Globalized Digital Age. IGI Global.

49. Richard L, Daft DM (2016) Job satisfaction. In Understanding Management. Cengage Learning.

50. Abraham J, Feldman R, Carlin C (2004) Understanding employee awareness of health care quality information: how can employers benefit? Health Serv Res 39: 1799-1815. 